\title{
Preliminary Review of Safety Assessment Issues at Savannah River Site, August 2011
}

Report to Savannah River Nuclear Solutions (SRNS)

\author{
BA Napier \\ JP Rishel \\ NE Bixler
}

September 2011 


\title{
DISCLAIMER
}

This report was prepared as an account of work sponsored by an agency of the United States Government. Neither the United States Government nor any agency thereof, nor Battelle Memorial Institute, nor any of their employees, makes any warranty, express or implied, or assumes any legal liability or responsibility for the accuracy, completeness, or usefulness of any information, apparatus, product, or process disclosed, or represents that its use would not infringe privately owned rights. Reference herein to any specific commercial product, process, or service by trade name, trademark, manufacturer, or otherwise does not necessarily constitute or imply its endorsement, recommendation, or favoring by the United States Government or any agency thereof, or Battelle Memorial Institute. The views and opinions of authors expressed herein do not necessarily state or reflect those of the United States Government or any agency thereof.

\author{
PACIFIC NORTHWEST NATIONAL LABORATORY \\ operated by \\ BATTELLE \\ for the \\ UNITED STATES DEPARTMENT OF ENERGY \\ under Contract DE-AC05-76RL01830
}

Printed in the United States of America
Available to DOE and DOE contractors from the Office of Scientific and Technical Information,
P.O. Box 62, Oak Ridge, TN 37831-0062;
ph: (865) 576-8401
fax: $(865)$ 576-5728
email: reports@adonis.osti.gov

\begin{abstract}
Available to the public from the National Technical Information Service, U.S. Department of Commerce, 5285 Port Royal Rd., Springfield, VA 22161 ph: (800) 553-6847 fax: $(703) 605-6900$ email: orders@ntis.fedworld.gov online ordering: http://www.ntis.gov/ordering.htm
\end{abstract}

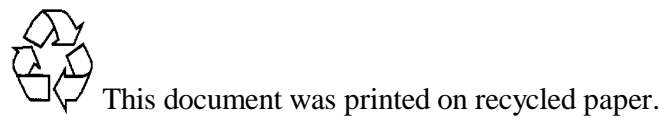




\section{Preliminary Review of Safety Assessment Issues at Savannah River Site, August 2011}

Report to Savannah River Nuclear Solutions (SRNS)

BA Napier

JP Rishel

NE Bixler

September 2011

Pacific Northwest National Laboratory

Richland, Washington 99352 


\section{Acronyms and Abbreviations}

$\begin{array}{ll}\begin{array}{l}\text { DNFSB } \\ \text { DOE }\end{array} & \begin{array}{l}\text { Defense Nuclear Facility Safety Board } \\ \text { Department of Energy }\end{array} \\ \text { EPA } & \text { Environmental Protection Agency } \\ \text { MACCS2 } & \text { MELCOR Accident Consequence Code System } \\ \text { NRC } & \text { Nuclear Regulatory Commission } \\ \text { PG } & \text { Pasquill Gifford } \\ \text { PNNL } & \text { Pacific Northwest National Laboratory } \\ \text { RG } & \text { Regulatory Guide } \\ \text { SNL } & \text { Sandia National Laboratory } \\ \text { SRNS } & \text { Savannah River Nuclear Solutions } \\ \text { SRS } & \text { Savannah River Site }\end{array}$




\section{Contents}

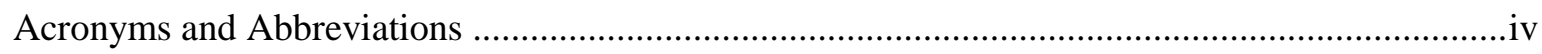

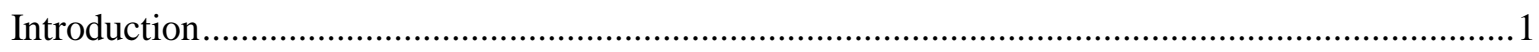

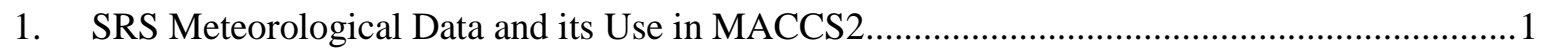

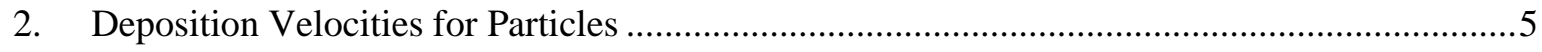

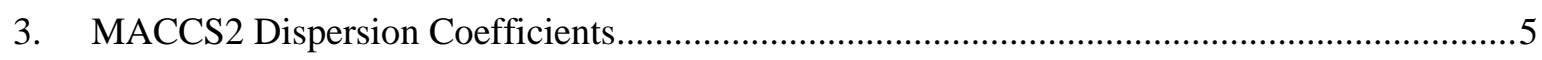

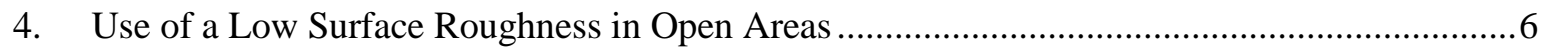

5. Adequacy of Meteorological Tower and Instrumentation ....................................................6

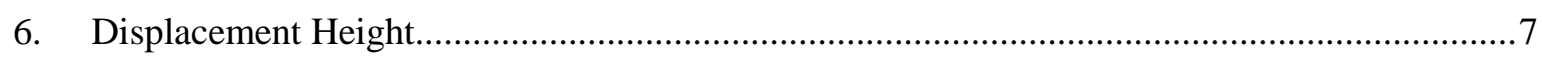

7. Validity of MACCS2 Calculations at Close-in Distances .....................................................

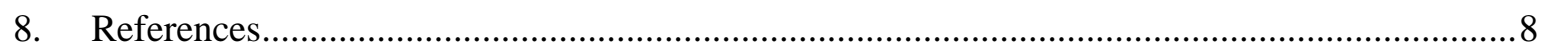




\section{Figures}

Figure 1.1: Histogram of SRS PG Stability Class for 1999 Using the NRC Draft RG 1.23 SigmaTheta Method

Figure 1.2: Histogram of Vogtle PG Stability Class for 1999 Using the NRC Temperature

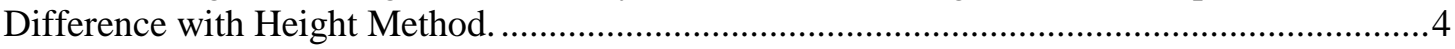




\section{Introduction}

At the request of Savannah River Nuclear Solutions (SRNS) management, a review team composed of experts in atmospheric transport modeling for environmental radiation dose assessment convened at the Savannah River Site (SRS) on August 29 - 30, 2011. Invited participants were Bruce Napier and Jeremy Rishel, Pacific Northwest National Laboratory (PNNL), and Nathan Bixler, Sandia National Laboratory (SNL). Napier is an environmental health physicist and the developer of the GENII software package. Rishel is a meteorologist with experience in radiological safety assessments. Bixler is the principal investigator and custodian for the MACCS2 computer code.

Several issues were presented at the meeting for discussion. This is a short summary that is organized in accordance with the primary issues discussed, which is not necessarily a chronological record. A longer report will be issued at a later date that expands upon these topics and recommendations.

\section{SRS Meteorological Data and its Use in MACCS2}

The SRS site uses a DOE-approved method for estimating Pasquill-Gifford (PG) stability class based upon the draft NRC Regulatory Guide (RG) 1.23 (NRC 1980). This technique is a turbulence-based method which relates the standard deviation of the horizontal wind direction (sigma-theta, $\sigma_{\theta}$ ) to corresponding PG stability classes (see Table 3, NRC 1980). The SRS meteorological data for the period 1997-2001 was processed in this manner (Hunter 2003). Though Section C.1 of the draft RG does mention several methods can be used to determine PG stability class, the guidance document states “...use of and classification by alternative estimators other than temperature difference with height should be justified and may also require modification of the models in Regulatory Guide 1.111 and Regulatory Guide 1.145 with appropriate justification." The draft RG does not provide guidance on what justifications or modifications may be necessary if the alternative methods, including $\sigma_{\theta}$, were to be used to determine PG stability class.

The Environmental Protection Agency (EPA) has since published guidance on methods for determining atmospheric stability classes from a variety of meteorological observations and measurements, including $\sigma_{\theta}$ (e.g., see EPA 2000, Section 6.4.4). With the exception of omitting stability class G, the EPA (see Table 6-9a, EPA 2000) defines an initial estimate of PG stability class using identical $\sigma_{\theta}$ ranges to the ones defined in the NRC draft RG 1.23 (see Table 3, NRC 1980). However, the EPA guidance includes further consideration of (a) adjustments to the $\sigma_{\theta}$ ranges for measurement height, (b) adjustments to the $\sigma_{\theta}$ ranges for surface roughness, and (c) a final adjustment to the PG stability class based on wind speed and time-of-day (i.e., daytime/nighttime). In short, these adjustments are used to normalize estimates of PG stability class by removing the effects of measurement height, mechanical turbulence created by sitespecific surface roughness elements, and meander under stable atmospheric conditions. Estimates of PG stability class using the $\sigma_{\theta}$, method, with these adjustments, generally should yield comparable estimates of PG stability class that would be obtained using other methods (e.g., Turner's method, the delta-T/delta- $Z$ method, etc.). 
The SRS meteorological data for the period 1997-2001 do not include the additional EPA adjustments. As a consequence, measurement height, surface roughness effects, and meander are inherent in the estimates of PG stability class (i.e., they have not been removed). The review team concludes that the overall impact of not making these adjustments is that the SRS estimates of PG stability class are shifted towards more unstable conditions. To support this conclusion, the review team compared a histogram of PG stability class for the year 1999 at SRS (Figure 1.1) to the nearby Vogtle Nuclear Station (Figure 1.2). Vogtle estimates of PG stability class are made using measurements of temperature difference with height (i.e., delta-T/delta-Z; NRC 2008).

The comparison of the methods is illustrative of how much of a shift may be present in the SRS estimate of PG stability class as a result of not making the adjustments. As the figures clearly show, there are many more unstable cases (PG stability classes A, B, C) in the SRS dataset (Figure 1.1) than in the Vogtle dataset (Figure 1.2); there are comparatively very few extremely stable cases (PG stability classes F and G) in the SRS dataset. With the Vogtle histogram for PG stability classes, the $95^{\text {th }}$ percentile result for dose is likely to correspond to $\mathrm{G}$ stability; with the SRS histogram for PG stability classes, the $95^{\text {th }}$ percentile result for dose is likely to correspond to E stability. The review team estimates that this corresponds to roughly a two-stability-class shift in the data.

MACCS2 includes a scaling factor, ZSCALE, to account for the effects of surface roughness on vertical plume diffusion. The suggested ZSCALE scaling factor (Chanin and Young 1998) is given by the formula:

$$
\left(\mathrm{Z}_{\mathrm{o}} / 3.0\right)^{0.2}
$$

where $Z_{o}$ is the site-specific surface roughness in $\mathrm{cm}$. If the site-specific surface roughness is greater than $3 \mathrm{~cm}$, the ZSCALE factor is greater than 1.0, and the site-specific surface roughness is credited with enhancing vertical diffusion. The SRS site is predominately forested; the sitespecific surface roughness is estimated to be around $100 \mathrm{~cm}$, resulting in a ZSCALE scaling factor of 2.02 in MACCS2.

The review team notes that because of the shift towards more unstable PG stability classes that is inherent in the 1997-2001 SRS dataset, use of this data in MACCS2 will automatically result in larger vertical (and lateral) plume diffusion. Therefore, the review team's short-term recommendation is to not credit the site-specific surface roughness for enhanced vertical diffusion in MACCS2; this can be accomplished by setting the ZSCALE scaling factor to 1.0. As a result, doses will go up by a factor of 2.02 at short distances and when deposition is negligible. The factor of 2.02 in predicted doses does not generalize to situations where the plume becomes well mixed within the mixing layer or where deposition significantly depletes the plume. The review team's long-term recommendation is for SRS to fully implement the EPA guidance by including the adjustments for measurement height, surface roughness, and wind speed/time-of-day. If these adjustments are implemented, then the ZSCALE scaling factor of 2.02 should be used in MACCS2 to correct for the site-specific surface roughness. 
Finally, the review team notes that SRS wind speeds, which are measured at $61 \mathrm{~m}$, are scaled down to a 10-m level for use in MACCS2. The scaling procedure is documented in the meteorological processing report that accompanies the 1997-2001 dataset (Hunter 2003); the wind speed scaling method implements, and is consistent with, EPA guidance (EPA 2000). However, because the scaling is functionally dependent on PG stability class, the review team expects that estimates of scaled wind speeds will also change once the long-term recommendation of reprocessing the data is implemented. Review of the wind speed scaling relationship indicates that scaled wind speeds at the 10-m level will go down somewhat, and doses will therefore go up because predicted doses are inversely proportional to wind speed. 


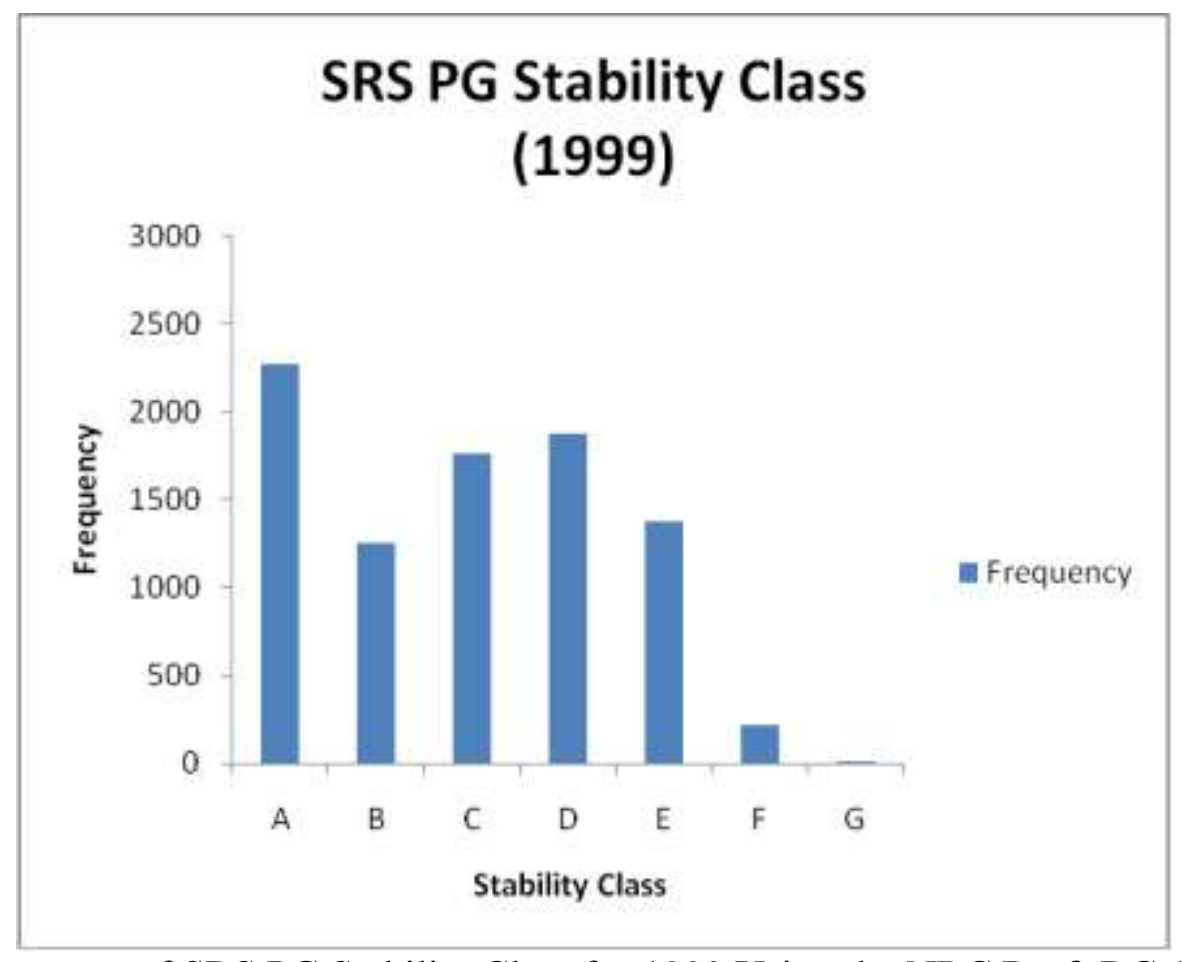

Figure 1.1: Histogram of SRS PG Stability Class for 1999 Using the NRC Draft RG 1.23 SigmaTheta Method

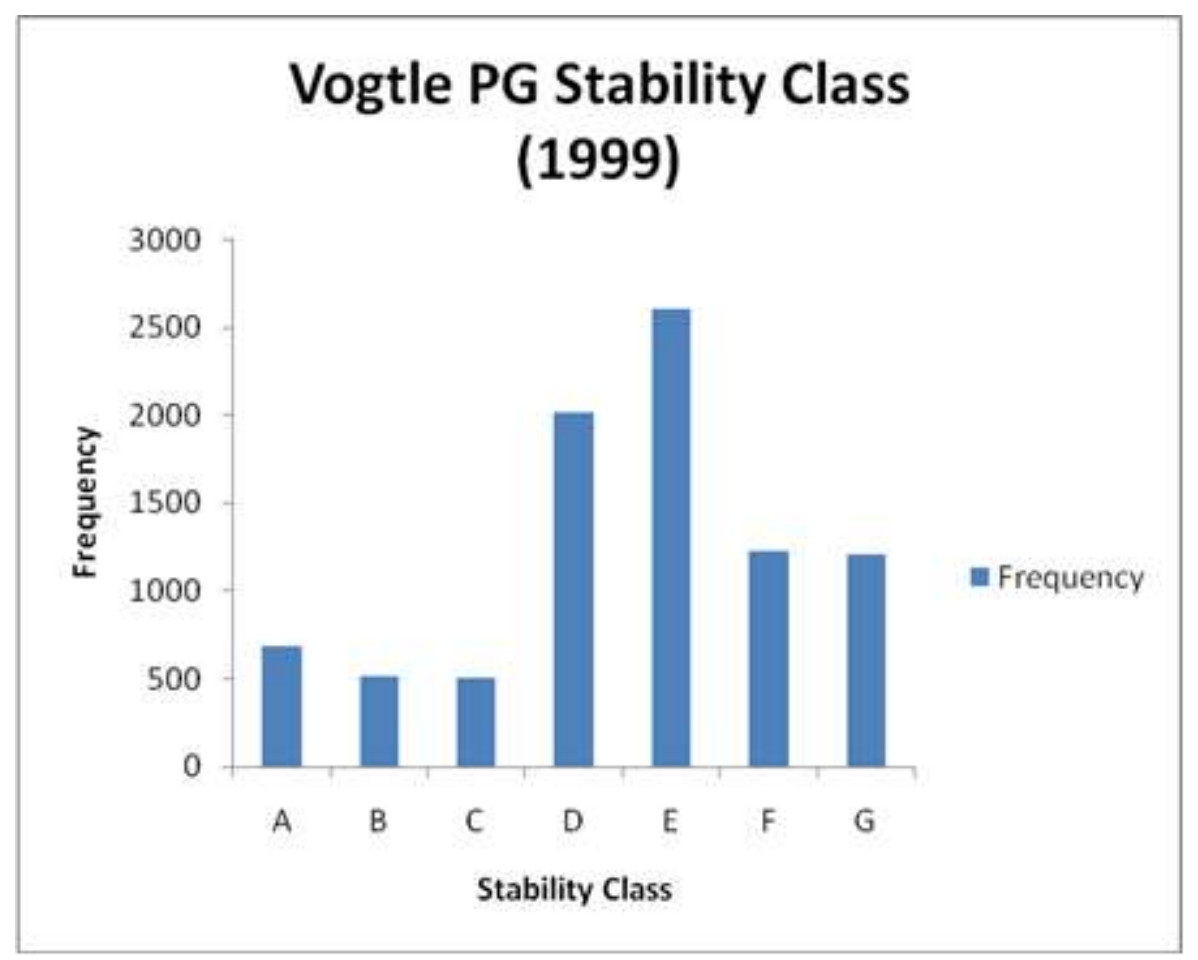

Figure 1.2: Histogram of Vogtle PG Stability Class for 1999 Using the NRC Temperature Difference with Height Method. 


\section{Deposition Velocities for Particles}

Dispersion and dose calculations performed with MACCS2 over the past decade have used values of deposition velocity that were recommended in Department of Energy (DOE) guidance. Recent Defense Nuclear Facility Safety Board (DNFSB) recommendations have been adopted as interim guidance by DOE that reduce the deposition velocities by factors of 10, with the option to use well-documented site-specific values. The review team recommendation is to calculate site-specific deposition velocities using the GENII Version 2.10 computer code (Napier et al. 2010) using surface roughness inputs of $3 \mathrm{~cm}, 30 \mathrm{~cm}$, and $100 \mathrm{~cm}$. Bruce Napier will identify the needed parameters; SRNS staff members will provide the SRS-specific values with references. Bruce Napier will then use GENII Version 2.10 to calculate SRS-specific deposition velocities for unfiltered and filtered releases and document the results in a technically-reviewed report, including references describing the GENII status regarding inclusion in the DOE toolbox of safety assessment codes (DOE 2011).

\section{MACCS2 Dispersion Coefficients}

The MACCS2 code allows for the use of different parameterizations of the lateral $\left(\sigma_{\mathrm{y}}\right)$ and vertical $\left(\sigma_{\mathrm{z}}\right)$ diffusion coefficients. Current practice at SRS has been to use the parameterization of Tadmor and Gur (1969). Recent inquiries by the DNFSB have suggested that the parameterization of Briggs might be a better choice. The review team has performed some preliminary dispersion calculations using the GENII code (Napier et al. 2010) for the distances of interest at SRS (100 m to about $11 \mathrm{~km}$ ) to compare the Tadmor-Gur and Briggs methods; additional parameterizations available in the GENII code include Eimutis and Konicek (1972), as well as the rural parameterization used in the EPA's Industrial Source Complex (ISC3) Model (EPA 1995). The Eimutis and Konicek dispersion parameterizations have been used in past NRC dispersion models, including XOQDOQ (Sagendorf et al. 1982) and PAVAN (Bander 1982). Similar calculations were performed with MACCS2 by SRNS and reviewed by the review team. Both sets of calculations lead to the same conclusions.

The preliminary comparison showed that all of the parameterizations are essentially indistinguishable in the distances of interest at SRS site, with the exception of Tadmor-Gur at $100 \mathrm{~m}$. Most of the parameterizations use three to five different equations as functions of distance for the parameterization. However, the Tadmor-Gur method uses only two equations in the parameterization, and this is likely to be the cause for the apparent disagreement of the Tadmor-Gur correlation at $100 \mathrm{~m}$. Based on the preliminary comparison, the review team concludes that all methods are acceptable parameterizations, except Tadmor-Gur at $100 \mathrm{~m}$.

The review team notes that the Briggs parameterizations begin to diverge from the other PG parameterizations at distances beyond about $10 \mathrm{~km}$. Briggs used additional data in formulating the parameterizations at longer distances. Briggs also has separate parameterizations for rural and urban areas. Therefore, in discussions of Briggs, it has been stated that Briggs' parameterizations are 'independent' of surface roughness. The review team understands this logic but questions its correctness in specific applications because the Briggs rural 
parameterizations are essentially the same as the other parameterizations at distances less than 10 $\mathrm{km}$.

As a consequence, the review team notes that there is some question as to whether it is appropriate to credit surface roughness with the vertical scaling factor (ZSCALE) in MACCS2 when using the Briggs parameterization. At best, use of a vertical scaling factor with the Briggs parameterizations is clouded by the fact that it is based on measurements that are for a range of surface roughnesses rather than for a single value of surface roughness. Therefore, the review team considers the Eimutis and Konieck dispersion parameterizations or a lookup table of values taken directly from the PG curves to be most appropriate for the SRS site. Either of these two options would allow for crediting of the site-specific surface roughness in MACCS2 through the ZSCALE scaling factor, once the SRS meteorological data has been reprocessed to include all of the EPA adjustments.

\section{Use of a Low Surface Roughness in Open Areas}

DOE guidance directs the use of specific MACCS2 inputs in safety assessments. One value recommended related to the discussions above is to use a surface roughness value of $3 \mathrm{~cm}$ when estimating doses to co-located workers. The assumption behind this recommendation is that colocated workers will be in open areas around nearby facilities. The effect of this recommendation is that the ZSCALE scaling factor used to adjust the vertical diffusion parameters to take account of surface roughness would be set to 1.0 (i.e., no enhancement to vertical dispersion through site-specific surface roughness elements).

The review team needs to look more closely at the intent of the DOE guidance. Given the considerations discussed above concerning the SRS meteorological data and its use in MACCS2, this may be a moot point if DOE does indeed require no additional credit to vertical diffusion from site-specific surface roughness elements. Also, it should be noted that the importance of surface roughness on predicted doses to co-located workers is significantly reduced when the source is treated as an area source rather than as a point source; this is discussed further in "Validity of MACCS2 Calculations at Close-in Distances".

\section{Adequacy of Meteorological Tower and Instrumentation}

There are nine meteorological monitoring locations at SRS, including towers at A, C, D, F, H, K, L, and P (Hunter 2003). Data recorded at the H-Area tower was used to develop the 1997-2001 MACCS2 meteorological files (Hunter 2003). The review team visited the C-Area meteorological tower to examine the site as well as the meteorological instrumentation. The CArea tower is representative of many of the towers at SRS; it is instrumented at the 61-m level with wind and temperature sensors. The tower is surrounded uniformly in all directions by a variety of deciduous and evergreen trees. SRS also maintains a multi-level instrumented climate tower (called CLM) that is located in an open area that is used for generating climate statistics for the site.

Although the review team did not perform a complete review or evaluation of the SRS meteorological monitoring program, the towers appear to be measuring meteorological data that 
is representative of the SRS site. Additionally, the towers are well positioned and routinely maintained for the purposes of reliably measuring meteorological data for use in a safety analysis. The review team believes the standard deviation of the horizontal wind direction (sigma-theta, $\sigma_{\theta}$ ), which is used at SRS to estimate PG stability class in MACCS2, is appropriate if all of the EPA adjustments (see "SRS Meteorological Data and its Use in MACCS2") are applied to the data.

\section{Displacement Height}

When making the wind speed height adjustment from $61 \mathrm{~m}$ to $10 \mathrm{~m}$ for input to the MACCS2 code, the current calculation conservatively uses the ground rather than the top of the canopy as the reference point. The review team suggests that a displacement height created by the trees be considered (essentially the top of the tree canopy) when the effective zero height is estimated. This would have the impact of slightly increasing the assumed release height wind speed, because the distance from the measurement point to the 10 meter point will be less. This modification to the weather data processing is expected to partially offset the decrease in estimated $10-\mathrm{m}$ wind speed that will result when stability classes are corrected according to the EPA guidance, as described in "SRS Meteorological Data and its Use in MACCS2".

\section{Validity of MACCS2 Calculations at Close-in Distances}

Several issues were noted by the review team with the current method for evaluating doses to colocated workers at close-in distances of $100 \mathrm{~m}$. First, it is well recognized that Gaussian plume models are not capable of accurately representing doses at such close distances. For example, the MACCS2 user's guide (Chanin and Young 1998) states on p. 5-4 that "The Gaussian plume dispersion parameterizations commonly available (see Section 5.7) are likely to be of limited value at distances less than $0.5 \mathrm{~km}$ because of building wake effects." However, to compensate for this shortcoming, MACCS2 allows the user to include the effects of a building wake by treating the source as an area source instead of a point source. While the building wake model in MACCS2 is highly approximate, it at least provides estimates at short distances that are more defensible than would be obtained by assuming a point source. However, DOE guidance currently prescribes that a point source be used even for doses to co-located workers, resulting in extraordinarily conservative predictions of dose. Using the MACCS2 area-source approximation for a building wake would allow for a more reasonable prediction of dose to a co-located worker. The review team recommends that DOE guidance be modified to recommend use of area sources rather than point sources, especially for estimation of doses to co-located workers.

Related to this issue is the appropriate value of the vertical diffusion scaling factor (ZSCALE) to use for estimating doses at short distances, as discussed above. When the source is treated as a point source, the predicted dose is inversely proportional to this scaling factor, and thus the scaling factor is an important parameter. Current DOE guidance is to use a 3-cm surface roughness when performing this prediction. However, if the source were treated as an area source, the value of ZSCALE would have a secondary effect on the predicted dose to a colocated worker. Instead, the predicted dose would be dominated by the height and width of the building because these would control the dimensions of the area source. 


\section{References}

Bander T.J. 1982. PAVAN: An Atmospheric Dispersion Program for Evaluating Design Basis Accidental Releases for Radioactive Materials from Nuclear Power Stations. Nuclear Regulatory Commission. NUREG/CR-2858.

Chanin D.I. and M.L. Young. 1998. Code Manual for MACCS2: Volume 1, User's Guide. Sandia National Laboratories. SAND97-0594.

Department of Energy (DOE). 2011. Software Evaluation of GENII V2.10 with FRAMES V1.7 for Inclusion in the DOE Safety Software Central Registry. Office of Health, Safety and Security, Washington, DC. Draft June 2011, DOE/HS-000X.

Eimutis E.C. and M.G. Konicek. 1972. Derivations of Continuous Functions for the Lateral and Vertical Atmospheric Dispersion Coefficients. Atmospheric Environment 6:859-63.

Environmental Protection Agency (EPA). 1995. User's Guide for the Industrial Source Complex (ISC3) Dispersion Models; Volume II - Description of Model Algorithms. Office of Air Quality Planning and Standards. EPA-454/B-95-003b.

Environmental Protection Agency (EPA). 2000. Meteorological Monitoring Guidance for Regulatory Modeling Applications. Office of Air Quality Planning and Standards. EPA-454/R99-005.

Fellows, R.J., D.A. Cataldo, M.W. Ligotke, and B.A. Napier. 1990. Transfer of Atmospheric Tritiated Water to Foliage and Fruit of Crops. Pacific Northwest Laboratory. PNL-7521.

Hunter, C H. 2003. Five-Year Meteorological Data Base for the MACCS Computer Code. Westinghouse Savannah River Company. WSRC-RP-2003-00608.

Napier B. A., D.L. Stenge, J.V. Ramsdell Jr., P.W. Eslinger, and C.J. Fosmire. 2010. GENII Version 2 Software Design Document. Pacific Northwest National Laboratory. PNNL-14584 Rev 3.

Nuclear Regulatory Commission (NRC). 1980. Proposed Revision 1 to Regulatory Guide 1.23 Meteorological Programs in Support of Nuclear Power Plants.

Nuclear Regulatory Commission (NRC). 2008. Final Environmental Impact Statement for an Early Site Permit (ESP) at the Vogtle Electric Generating Plant Site. NUREG-1872, Vol. 1.

Sagendorf J.F., J.T. Goll, and W.F. Sandusky. 1982. XOQDOQ: Computer Program for the Meteorological Evaluation of Routine Effluent Releases at Nuclear Power Stations. Nuclear Regulatory Commission. NUREG/CR-4380.

Tadmor, J., and Y. Gur. 1969. Analytical Expressions for the Vertical and Lateral Dispersion Coefficients in Atmospheric Diffusion. Atmospheric Environment, Vol. 3, pp. 688-689. 


\section{Distribution}

Savannah River Nuclear Solutions (SRNS)

Scott Elliot

(PDF)

Sandia National Laboratory (SNL)

Nate Bixler

(PDF)

Pacific Northwest National Laboratory (PNNL)

Bruce Napier

(PDF)

Jeremy Rishel

(PDF)

Distr.1 


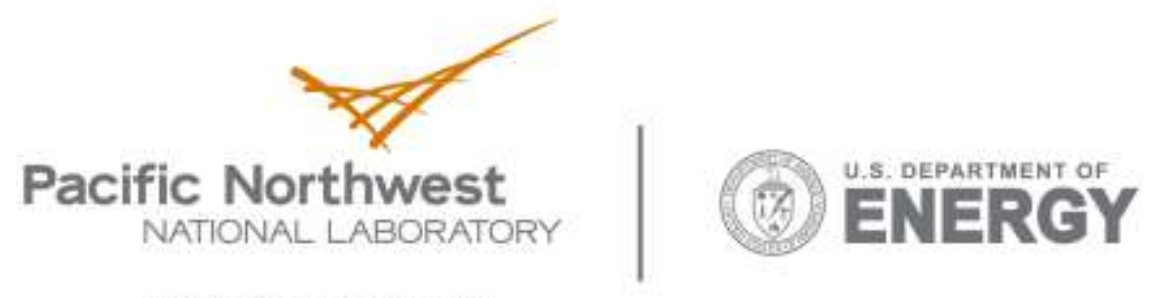

902 Battelle Boulevard

P.O. Box 999

Richland, WA 99352

1-888-375-PNNL (7665)

www.pnl.gov 